\title{
Characterization of carbonaceous aerosols during the MINOS campaign in Crete, July-August 2001: a multi-analytical approach
}

\author{
J. Sciare ${ }^{1,}{ }^{*}$, H. Cachier ${ }^{2}$, K. Oikonomou ${ }^{3,}$, , P. Ausset ${ }^{4}$, R. Sarda-Estève ${ }^{2}$, and N. Mihalopoulos ${ }^{3}$ \\ ${ }^{1}$ Department of Biogeochemistry, Max-Planck-Institute for Chemistry, Mainz, Germany \\ ${ }^{2}$ Laboratoire des Sciences du Climat et de l'Environnement (LSCE), Gif-sur-Yvette, France \\ ${ }^{3}$ Department of Chemistry, University of Crete, Heraklion, Crete, Greece \\ ${ }^{4}$ Laboratoire Interuniversitaire des Systèmes Atmosphériques (LISA), Créteil, France \\ *now at LSCE
}

Received: 13 May 2003 - Published in Atmos. Chem. Phys. Discuss.: 1 July 2003

Revised: 2 October 2003 - Accepted: 10 October 2003 - Published: 16 October 2003

\begin{abstract}
During the major part of the Mediterranean Intensive Oxidant Study (MINOS) campaign (summer 2001, Crete Isl.), the Marine Boundary Layer (MBL) air was influenced by long range transport of biomass burning from the northern and western part of the Black Sea. During this campaign, carbonaceous aerosols were collected on quartz filters at a Free Tropospheric (FT) site, and at a MBL site together with size-resolved distribution of aerosols. Three Evolution Gas Analysis (EGA) protocols have been tested in order to better characterize the collected aged biomass burning smoke: A 2-step thermal method (Cachier et al., 1989) and a thermo-optical technique using two different temperature programs. The later temperature programs are those used for IMPROVE (Interagency Monitoring of Protected Visual Environments) and NIOSH 5040 (National Institute of Occupational Safety and Health). Artifacts were observed using the NIOSH temperature program and identified as interactions between carbon and dust deposited on the filter matrix at high temperature $\left(\mathrm{T}>550^{\circ} \mathrm{C}\right)$ under the pure helium step of the analysis.

During the MINOS campaign, Black Carbon (BC) and Organic Carbon (OC) mass concentrations were on average respectively $1.19 \pm 0.56$ and $3.62 \pm 1.08 \mu \mathrm{gC} / \mathrm{m}^{3}$ for the IMPROVE temperature program, and $1.09 \pm 0.36$ and $3.75 \pm 1.24 \mu \mathrm{gC} / \mathrm{m}^{3}$ for the thermal method. Though these values compare well on average and the agreement between the Total Carbon (TC) measurements sample to sample was excellent (slope $=1.00, r^{2}=0.93, \mathrm{n}=56$ ), important discrepancies were observed in determining $\mathrm{BC}$ concentrations from these two methods (average error of $33 \pm 22 \%$ ). BC from the IMPROVE temperature program compared well with nonsea-salt potassium (nss-K) pointing out an optical sensitivity to biomass burning. On the other hand, $\mathrm{BC}$ from the thermal method showed a better agreement with non-sea-salt sulfate
\end{abstract}

Correspondence to: J. Sciare

(sciare@1sce.saclay.cea.fr)
(nss-SO $\mathrm{S}_{4}$ ), considered as a tracer for fossil fuel combustion during the MINOS campaign. The coupling between these two methods for determining $\mathrm{BC}$ brings here new insights on the origin of carbonaceous aerosols in a complex mixture of different sources. It brings also to our attention that important deviations in $\mathrm{BC}$ levels are observed using three widely used EGA's techniques and most probably none of the EGA tested here are well adapted to fully characterize this aerosol mixture.

Spherical, smooth and silico-aluminated fly-ash observed by an Analytical Scanning Electron Microscope (ASEM) confirm the influence of coal combustion on the carbonaceous aerosol load throughout the campaign. A rough calculation based on a $\mathrm{BC} / \mathrm{nss}-\mathrm{SO}_{4}$ mass ratio suggests that biomass burning could be responsible for half of the $\mathrm{BC}$ concentration recorded during the MINOS campaign.

From the plot of BC as a function of TC, two linear correlations were observed corresponding to 2 times series (before and after 12 August). Such good correlations suggest, from a first look, that both $\mathrm{BC}$ and $\mathrm{OC}$ have similar origin and atmospheric transport. On the other hand, the plot of $\mathrm{BC}$ as a function of TC obtained from the 2-step thermal method applied to DEKATI Low Pressure Cascade Impactor samples does not show a similar correlation and points out a non conservative distribution of this ratio with 2 super micron modes enriched in OC, correlated with sea salt aerosols and probably originating from gas-to-particle conversion.

\section{Introduction}

Since its adoption in the mid eighties, the Helsinki protocol on the reduction of sulfur emissions have brought sulfate and carbonaceous aerosols at the same concentration levels in the troposphere over Europe and the Mediterranean Sea (Krivacsy et al., 2001; Lelieveld et al., 2002). 
Carbonaceous aerosol is mainly a combustion aerosol of primary and secondary origin. This aerosol is usually separated in two main components: one is referred to as the organic carbon (OC) and the other as the black carbon (BC). $\mathrm{BC}$ radiative impact is significant because of its highly absorptive nature.

Recent model studies reproducing satellite observations (Jacobson, 2001) have demonstrated that BC aerosols were one of the three major components of aerosols (with sulfate and dust), which have very high direct radiative forcing at the top of the atmosphere in surrounding regions of the Mediterranean Basin. This model estimates a negative radiative forcing for aerosols in the Mediterranean, roughly comparable to that of greenhouse gases (e.g. -3 to $-4 \mathrm{~W} / \mathrm{m}^{2}$ ). During the MINOS campaign, the reduction of surface solar radiation was even larger $\left(-17.9 \mathrm{~W} / \mathrm{m}^{2}\right.$; Markowicz et al., 2002), demonstrating the important effect of absorbing aerosols in Mediterranean. These authors also noticed that the $\mathrm{BC}$ concentrations recorded during this campaign (see later on) were too low to entirely explain the forcing efficiency at the surface, and proposed, alternatively, a contribution of dust aerosols as another light absorbing material, which could explain their results. This assumption is supported first by important levels of dust aerosols observed at altitude over the Eastern Mediterranean (Andreae et al., 2002; Formenti et al., 2001 and 2002; Kouvarakis et al., 2002) second from the results of the EL CID campaign performed in Crete Isl. in summer 2000 (exactly a year before the MINOS campaign) which showed significant bias in BC calculation based on light absorbance during dust events (Sciare et al., 2003). As a result, there is a great need to better investigate the role of carbonaceous aerosols, their origin and physical, chemical and optical properties in the eastern Mediterranean.

As emphasized by Huebert and Charlson (2000), there are still very large uncertainties in all the published EGA protocols for determining $\mathrm{BC}$ and $\mathrm{OC}$ content in aerosols, including very similar ones such as thermo-optical protocols (Chow et al., 2001, Yu et al., 2002, Yang and Yu, 2002). If most of these protocols give a good agreement in TC determination, BC concentrations differ substantially for ambient aerosols (Schmid et al., 2001). They usually compare within $20 \%$ for urban aerosols but deviations are more important for remote aerosols (e.g. the aerosols collected during MINOS). Running several of these protocols for the same samples, as it is proposed here, will help us to understand the uncertainties in carbon analysis. The work presented here will aim to better characterize $\mathrm{BC}$ and $\mathrm{OC}$ concentrations over the eastern Mediterranean during the MINOS campaign from different analytical protocols: A 2-step thermal method (Cachier et al., 1989) and a thermo-optical technique using two different temperature programs (NIOSH and IMPROVE) and a red light laser transmittance $(660 \mathrm{~nm}$ with a $10 \mathrm{~nm}$ bandpass). Origin of carbonaceous aerosols will be discussed from back trajectory analysis, Scanning Electron Microscope
(SEM) pictures, comparison between MBL and FT sites, and $\mathrm{BC} / \mathrm{TC}$ ratio variability.

\section{Instrumentation}

\subsection{Sampling sites and overview of the campaign}

Two ground-based stations (Finokalia and Skinakas) were operating during the MINOS campaign: Finokalia station located in the MBL $\left(35^{\circ} 19^{\prime} \mathrm{N}, 25^{\circ} 40^{\prime} \mathrm{E} ; 150 \mathrm{~m}\right.$ above sea level (asl)) was running for the period 25 July-23 August 2001; Skinakas station, located in the FT $\left(35^{\circ} 15^{\prime} \mathrm{N}, 2^{\circ} 50^{\prime} \mathrm{E}\right.$; $1500 \mathrm{~m}$ asl) and at $50 \mathrm{~km}$ from the MBL site, was running for the period 29 July-19 August 2001. These 2 stations were situated within 2 different aerosol layers (0-1200 m and $1200-3000 \mathrm{~m}$ ) as observed from the vertical profiles of aerosols properties carried out through all the campaign from flight measurements (Minikin et al., unpublished results).

Results from the Hysplit Dispersion Model (Hybrid Single - Particle Langrangian Integrated Trajectory; Draxler and Hess, 1998) indicate that at the MBL site and for the whole duration of the campaign, air masses originated exclusively from central and eastern Europe, in agreement with the results of Salisbury et al. (2003). The FT site was influenced by air masses originating from both central, eastern and western Europe, in agreement with the results reported by Lelieveld et al. (2002).

\subsection{Aerosol sampling}

Ambient aerosols were collected every $12 \mathrm{~h}$ on 47-mm diameter quartz filters (QMA, Whatman) for carbon analysis, and on Stack Filter Units (SFUs) for gravimetric measurements and ion analysis. Ion analysis is described by Kouvarakis and Mihalopoulos (2002).

SFUs consist of an $8 \mu \mathrm{m}$ pore size $47-\mathrm{mm}$ diameter $\mathrm{Nu}-$ clepore filter mounted in front of a $0.4 \mu \mathrm{m}$ pore size $47-\mathrm{mm}$ diameter Nuclepore Filter. All filters are weighed prior to exposure. The $50 \%$ cut point diameter $\left(D_{50}\right)$ of the $8 \mu \mathrm{m} \mathrm{Nu}-$ clepore filter was estimated to be of the order of $1.2 \pm 0.1 \mu \mathrm{m}$ for the adopted flowrate. A total of 56 quartz filters and SFUs were collected at the MBL site (26 July-23 August 2001); 6 quartz filters and 15 SFUs were collected at the FT site (31 July-18 August 2001). Flow rate was on average $51 \pm 4$ Liter per minute $(\mathrm{Lpm})$ and pressure drops around $100 \mathrm{mbar}$ for the quartz filters collected in the field. Quartz filters, were baked for 24 hours at $600^{\circ} \mathrm{C}$. Several blanks were taken on the field and analyzed together with the samples (see later on).

Size-segregated aerosols were collected on a 3-day basis at the MBL site using in parallel two low-pressure cascade impactors; a 11-stage Micro-Orifice Uniform Deposit Impactor (MOUDI, MSP Corporation) operating with 47-mm diameter Nuclepore polycarbonate and teflon filters, for mass, ion, 
particle-induced X-ray emission (PIXE), short irradiation Instrumental Neutron Activation Analysis (INAA), and optical absorption measurements; and a 13-stage Low pressure cascade Impactor (DEKATI, Dekati Ltd, Tampere, Finland) operating with 25-mm diameter Glass fibre (GFC) filters for BC and $\mathrm{OC}$ measurements using the thermal protocol developed by Cachier et al. (1989).

\section{Analysis}

\subsection{Carbonates in aerosols}

Carbonates in aerosols play an important role in the carbon analysis as they can interfere the measurement by releasing $\mathrm{CO}_{2}$ at high temperatures in the range $550-1020^{\circ} \mathrm{C}$ (Webb and Kruger, 1970). In a dusty environment such as Crete Isl., this BC positive artifact should be significant especially for our quartz filters, sampled with no cut-off at the inlet and thus capable of collecting dust aerosols. Carbonates levels in the aerosol can be roughly estimated following the calculations done by Bardouki et al. (2003) and assuming a single dust origin $\left(\mathrm{CaCO}_{3}\right)$ and using PIXE - INAA analysis of dust end members obtained during the MINOS campaign (such as $\mathrm{Fe}, \mathrm{Al}, \mathrm{Si}, \mathrm{Ca}$, results from MOUDI cascade Impactor; Sciare et al., unpublished results). In our samples, the mass percentage of carbon from carbonates would represent $2-15 \%$ (average $=6.1 \pm 2.6$ ) for the MBL site and $8-13 \%$ (average $=10.3 \pm 2$ ) for the FT site.

Thus for all the EGA, all the samples were previously decarbonated by $\mathrm{HCl}$ fumes using the protocol designed by Cachier et al. (1989). Following decarbonatation, 2 standard sized punches of $1 \times 1.45 \mathrm{~cm}$ were taken from the quartz filters for thermo-optical analysis, the rest of the quartz filters being dedicated to the thermal analysis.

\subsection{Thermo-optical methods}

We used a Sunset thermo-optical transmission carbon analyzer system (Sunset Lab., OR, USA) for determining BC and OC in aerosols. The Sunset instrument measurements are performed from standard sized punch of the quartz filters, through temperature and gas control, and by a laser transmission that corrects for the pyrolytically generated "EC" (or char) formed during the analysis of OC materials. The analysis needs two distinct stages. In the first, OC is volatilized from the sample in a pure helium atmosphere. In the second, $\mathrm{BC}$ and pyrolytically generated "BC" are oxidized under a mix of $2 \%$ of oxygen in ultra high purity (UHP) helium with a concurrent increase in the filter transmittance. Correction for the charring contribution to $\mathrm{BC}$ is performed by identifying the point at which the filter transmittance reaches its initial value. Carbon evolved before this split point is considered as OC; carbon evolved after this split point and prior to the peak used for the instrument calibration (final peak) is
Table 1. Experimental parameters of the two thermo-optical methods used in this study

\begin{tabular}{lll}
\hline Carrier Gas & $\begin{array}{l}\text { NIOSH } \\
\text { Temp program }\end{array}$ & $\begin{array}{l}\text { IMPROVE } \\
\text { Temp program }\end{array}$ \\
\hline $\mathrm{He}-1$ (OC1) & $310^{\circ} \mathrm{C}, 60 \mathrm{~s}$ & $250^{\circ} \mathrm{C}, 150 \mathrm{~s}$ \\
$\mathrm{He}-2(\mathrm{OC} 2)$ & $475^{\circ} \mathrm{C}, 60 \mathrm{~s}$ & $450^{\circ} \mathrm{C}, 150 \mathrm{~s}$ \\
$\mathrm{He}-3(\mathrm{OC} 3)$ & $615^{\circ} \mathrm{C}, 60 \mathrm{~s}$ & $550^{\circ} \mathrm{C}, 250 \mathrm{~s}$ \\
$\mathrm{He}-4(\mathrm{OC} 4)$ & $870^{\circ} \mathrm{C}, 90 \mathrm{~s}$ & \\
$\mathrm{He} / \mathrm{O}_{2}{ }^{*}(\mathrm{BC} 1)$ & $550^{\circ} \mathrm{C}, 45 \mathrm{~s}$ & $550^{\circ} \mathrm{C}, 200 \mathrm{~s}$ \\
$\mathrm{He} / \mathrm{O}_{2}(\mathrm{BC} 2)$ & $625^{\circ} \mathrm{C}, 45 \mathrm{~s}$ & \\
$\mathrm{He} / \mathrm{O}_{2}(\mathrm{BC} 3)$ & $700^{\circ} \mathrm{C}, 45 \mathrm{~s}$ & $700^{\circ} \mathrm{C}, 160 \mathrm{~s}$ \\
$\mathrm{He} / \mathrm{O}_{2}(\mathrm{BC} 4)$ & $775^{\circ} \mathrm{C}, 45 \mathrm{~s}$ & \\
$\mathrm{He} / \mathrm{O}_{2}(\mathrm{BC} 5)$ & $850^{\circ} \mathrm{C}, 45 \mathrm{~s}$ & $850^{\circ} \mathrm{C}, 200 \mathrm{~s}$ \\
$\mathrm{He} / \mathrm{O}_{2}$ & $890^{\circ} \mathrm{C}, 120 \mathrm{~s}$ & \\
\hline
\end{tabular}

*A mix of $2 \%$ of oxygen in UHP helium.

BC. A more detailed description of the instrument is given by Birch and Cary (1996), Birch (1998) and Chow et al. (2001).

In this study, two temperature programs were implemented in the Sunset instrument and are summarized in Table 1. They correspond to the temperature programs used in the IMPROVE and NIOSH protocols (Chow et al., 1993; NIOSH, 1996 and 1998). Although these two protocols use different instruments and optical measurements, the main difference between these two protocols is originating from different temperature programs. It may be noted that a secondary cause of discrepancy between the NIOSH and IMPROVE protocols originates from the different optical correction and subsequent split time of the two instruments (Chow et al., 2001). This second cause is however minimized for nonheavy loaded filters such as our samples.

Determination of the split point between $\mathrm{BC}$ and $\mathrm{OC}$ and subsequent absorption measurement is also a critical point for determining the $\mathrm{BC}$ content of the filter (e.g. for both NIOSH and IMPROVE protocols). To minimize this absorption measurement and thus check the laser performance of the Sunset transmission, the following analytical strategy was applied: First, an 18-mm circle was taken from the quartz filter samples prior to decarbonatation. Aerosol attenuation of this circle was performed using a modified Aethalometer model AE-8 manufactured by Magee Scientific (Hansen et al., 1982). These absorption measurements have shown to be in very good agreement $\left(r^{2}=0.90 ; n=56\right)$ with absorption measurements performed in quasi real-time by the mean of a Particle Soot Absorption Photometer (PSAP, Radiance Research; Seattle, USA) (data not shown here). They were also in very good agreement $\left(r^{2}=0.93\right)$ with the absorption measurements performed by the laser beam of the Sunset instrument on the $1 \times 1.45 \mathrm{~cm}$ punches of the same quartz filters. This good agreement points out the good performance of the Sunset laser transmission measurements and its capability to better constrain the thermo-optical measurements. 


\subsection{Thermal method}

This method was used to determine the BC and OC concentrations from quartz filters (Cachier et al., 1989). sampled at the 2 sampling sites (bulk aerosol) and the GF/C filters sampled with the DEKATI Impactor.

The remaining part of the 47-mm quartz filters previously decarbonated is divided in two, one half gives TC (BC+OC). For the second half, the organic part is removed during a precombustion (at $340^{\circ} \mathrm{C}$ and under $\mathrm{O}_{2}$ for 2 hours) then the remaining black carbon is analyzed as $\mathrm{CO}_{2}$ by coulometric titration in a Ströhlein carbon analyzer. Carbon content is given by this instrument with an accuracy of $0.02 \mu \mathrm{g}$ (Liousse et al., 1993). The detection limit corresponds to a load on the order of $3 \mu \mathrm{g}$. The precision of the results is primary linked to the sample heterogeneity and has been estimated to be in the range of $10 \%$. This method gave comparable results as with various thermo-optical methods for a diesel soot intercomparison (Guillemin et al., 1997) and was in the range of $\pm 1 \sigma$ for $\mathrm{BC}$ and $\mathrm{TC}$ for the first stage round robin test for carbon aerosol (e.g. urban aerosols, Schmid et al., 2001). The calibration of the Ströhlein instrument was checked using either graphitic carbon standards or glucose solutions. The agreement between the two calibrations performed with liquid standards of glucose on both the Ströhlein and Sunset instruments was better than $1 \%$.

This thermal method has been also used for determining $\mathrm{BC}$ and $\mathrm{OC}$ content from a total of 5 runs of a 13-stage DEKATI cascade Impactor. $25 \mathrm{~mm}$ diameter $\mathrm{GF} / \mathrm{C}$ filters have been used for that purpose and were precleaned by a multisolvent (acetone, chloroform, ethanol) soxhlet extraction. Blanks (in $\mu \mathrm{gC}$ ) were reproducible and represented on average $5 \%$ and $15 \%$ of the BC and TC contents for the stages presenting the highest loading. Hereafter $\mathrm{BC}$ (Thermal) will refer to $\mathrm{BC}$ concentrations from this thermal method developed at LSCE.

\subsection{Sampling artifacts}

Artifacts due to the absorption of gas-phase organic compounds on the sample substrate were minimized by heating filters for $20 \mathrm{~min}$ at $60^{\circ} \mathrm{C}$ prior to the 2-step Thermal/Thermo-optical analysis. However, such artifacts do not impact significantly the determination of the light absorbing material of the aerosol (e.g. one of the major concerns of the MINOS campaign).

Very good agreement for BC and TC concentrations was obtained between our quartz bulk filters and the DEKATI cascade impactor samples which have been collocated throughout the campaign (Sciare et al., manuscript in preparation). The slope close to 1 found between the two sampling techniques - with all data points lying within a $10 \%$ errors in mass concentrations - suggests that sampling artifacts, which are not corrected by our pre-treatment at $60^{\circ} \mathrm{C}$, did not affect significantly the whole OC mass concentration of our sam- ples. Such conclusion reinforces the ability of our measurements to be used for the mass closure experiments of sub micron aerosols as performed by Sciare et al. (manuscript in preparation) during the MINOS campaign.

\section{Comparison between the different EGA protocols}

\subsection{Comparison between NIOSH and IMPROVE tempera- ture programs}

Figure 1 shows a thermogram obtained applying the NIOSH analysis protocol for one of the samples obtained at the MBL site. This figure shows that the laser transmission increases during the pure $\mathrm{He} 870^{\circ} \mathrm{C}$ step (OC4), clearly indicating important loss of a black component. Such a whitening of the sample has been reported in previous works which can be either due to an increased rate of reaction between oxygencontaining minerals and EC particles in the filter deposit (Chow et al., 2001), or due to the evolution of light absorbing organic material (present in wood smoke samples for instance). Yu et al. (2002) have also shown that this transmission increases with inorganic salts (such as ammonium sulfate). These three possibilities could occur during the analysis since our quartz filters collected a mixture of dust containing mineral oxides, biomass burning smoke and relatively high levels of ammonium sulfate.

It must however be noted that the whitening of the filter could not originate from the decomposition of carbonate since 1) our samples were pre-treated with $\mathrm{HCl}, 2$ ) carbonate does not absorb the red laser light.

\section{On the origin of the $\mathrm{BC}$ loss under pure helium}

Several tests were performed to better understand the origin of this analytical artifact. First, the IMPROVE Temperature program was applied to all our samples, without showing any loss of absorbing material under the pure $\mathrm{He}$ step. Such a result is expected since no BC loss was observed at the third plateau $\left(615^{\circ} \mathrm{C}\right)$ using the NIOSH temperature program (Fig. 1). Interestingly, although IMPROVE and $\mathrm{NIOSH}$ temperature program are reaching the same high temperatures under $\mathrm{He} / \mathrm{O}_{2}$ (i.e. $850-890^{\circ} \mathrm{C}$ ), only the quartz filters analyzed by the IMPROVE temperature program showed an orange color, probably due to the color of ironrich dust aerosols. This assumption was confirmed as the quartz filters presenting the most pronounced orange color corresponded to dusty events with dust loadings higher than $20 \mu \mathrm{g} / \mathrm{m}^{3}$.

Submitting these colored filters to the whole NIOSH temperature program did not show any change in the laser transmission, nor carbon evolved during this program. But more surprisingly the orange color of the filters disappeared whereas it previously remained during the IMPROVE temperature program. In other words, a fraction of dust aerosols 


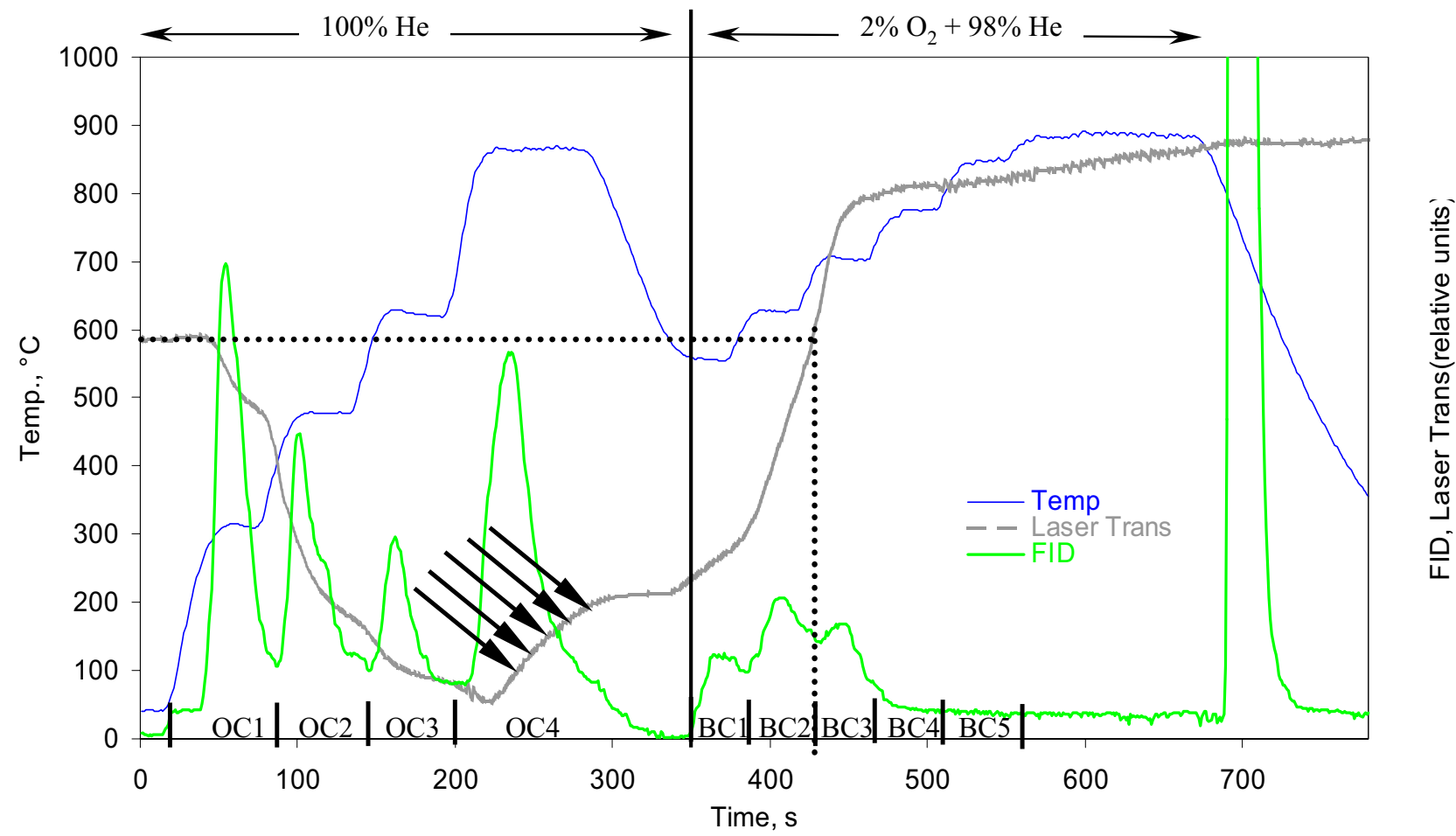

Fig. 1. NIOSH temperature program on a quartz filter sampled during MINOS. Black arrows indicate increase in laser transmission (BC loss) at the last temperature step $\left(870^{\circ} \mathrm{C}\right)$ under pure helium. OC1-5 and $\mathrm{BC} 1-5$ described in Table 1 have been reported here for each temperature step. The optical correction performed by the instrument is reported here (black dotted line) and represent the initial transmittance of the filter.

probably decomposed (and produce $\mathrm{O}_{2}$ ) under the pure helium step between 615 and $870^{\circ} \mathrm{C}$, and thus produced a partial thermal evolution of $\mathrm{BC}$ (aerosol or pyrogenic).

To verify this assumption, $20 \mu \mathrm{l}$ of glucose standards were used as a surrogate of pyrogenic BC and added to one of these orange filters. As expected, the thermogram clearly shows a decrease and then an increase in the laser transmission increase at $870^{\circ} \mathrm{C}$ during the last helium step (as observed in Fig. 1 with an actual environmental sample). Such a trend clearly indicates that $\mathrm{BC}$ produced from the pyrolysis of glucose is then released at this step in the presence of dust. Neither light absorbing organic or inorganic sea salt (such as ammonium sulfate) could explain this increase in transmission. Since important charring corrections may bring major uncertainties in $\mathrm{BC}$ assessment (Yang and $\mathrm{Yu}, 2002$ ) and as dust aerosols were ubiquous during the MINOS campaign, the IMPROVE temperature program was then the EGA protocol used for $\mathrm{BC}$ and $\mathrm{OC}$ determinations.

\section{On the choice of the last temperature step under pure Helium}

It is worthwhile noting here that the choice of this last temperature step under helium remains on open question.
Conny and Slater (2002) used a NIOSH protocol $\left(900^{\circ} \mathrm{C}\right.$ for the last Helium plateau) for the determination of $\mathrm{BC} / \mathrm{TC}$ ratios from fresh particles of crown fires in the Canadian forest. Their BC/TC ratio values range between 8 and $0.8 \%$ for flaming and smoldering stages respectively, and represent the lowest ratios proposed for biomass burning in the literature. These results would suggest that the $900^{\circ} \mathrm{C}$ for the last Helium plateau of the NIOSH protocol is too high as suggested Chow et al. (2001). Alternatively the last plateau fixed under helium by the IMPROVE protocol $\left(550^{\circ} \mathrm{C}\right)$ could be too low, involving a possible $\mathrm{OC}$ underestimation and $\mathrm{BC}$ overestimation and consequently a $\mathrm{BC} / \mathrm{TC}$ ratio which is too high. Figure 1 shows that at $615^{\circ} \mathrm{C}$ the laser transmission is still decreasing, suggesting strictly speaking, that $\mathrm{OC}$ is evolving at this temperature. However, a strict comparison between the two programs is not possible due to differences in plateau time duration. An alternative solution to analyze complex samples would be to design a temperature program with a prolonged last helium step until laser transmission is not changing and the evolution of carbon component has stopped. Such a procedure is however not totally satisfactory since the absorption coefficient of BC particles is likely to change while the $\mathrm{OC}$ component is escaping the filter matrix. This remark applies particularly to aged particles totally found as internal mixtures (Cachier, 1998). To avoid 


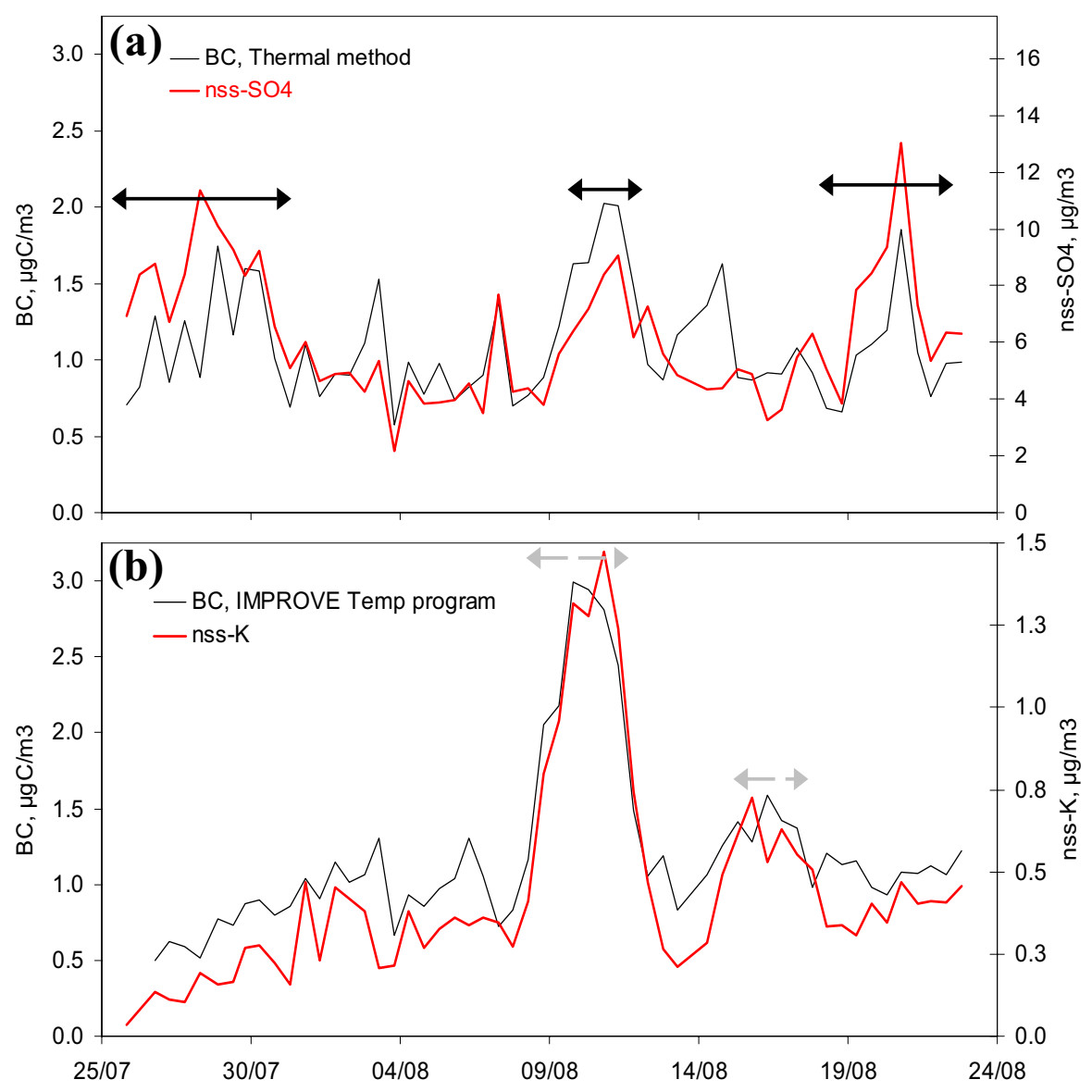

Fig. 2. $\mathrm{BC}$ from thermal method and nss-SO 4 concentrations (a); BC from thermo-optical IMPROVE method and nss-K (b) at the MBL site for the duration of the MINOS campaign. Black arrows correspond to the anthropogenic influence. Grey arrows correspond to the 2 biomass burning events of the campaign.

important loss of $\mathrm{BC}$ during the last helium step, we decided to adopt a last step of $550^{\circ} \mathrm{C}$ as described by the IMPROVE protocol.

Assuming 1) the last step under He being the most important parameter for $\mathrm{BC}$ calculation, 2) $550^{\circ} \mathrm{C}$ and $870^{\circ} \mathrm{C}$ being the minimal and maximal temperature which have to be set for this step, one can estimate the uncertainties in BC concentrations from the difference between NIOSH and IMPROVE temperature programs. In the case of our Crete samples, a difference as high as $50 \%$ was calculated for the averaged $\mathrm{BC}$ concentrations between these two methods (the IMPROVE temperature program giving higher $\mathrm{BC}$ concentrations). This difference can be considered as representative of the possible maximum error for the determination of $\mathrm{BC}$ concentrations given by a thermo-optical method.

\subsection{Comparison between thermo-optical (IMPROVE) and} 2-step thermal protocols

Such a comparison has been performed for the samples collected at the MBL and FT sites. The TC measurements compared very well for both sites with a slope of 1.0 and $r^{2}=0.93$ for all data points. Conversely important deviations were found for $\mathrm{BC}$, although on average, $\mathrm{BC}$ mass concentrations were comparable with $1.09 \pm 0.36 \mu \mathrm{g} / \mathrm{m}^{3}$ and $1.19 \pm 0.56 \mu \mathrm{g} / \mathrm{m}^{3}$ for 2-step Thermal and IMPROVE methods, respectively. Deviations as high as $88 \%$ were observed on individual samples between the two BC datasets (average error $=33 \pm 22 \%$ ). These results are somehow surprising since these two methods showed good agreement for urban aerosols (Cachier, 2003). On the other hand, one must keep in mind that part of carbonaceous aerosols sampled during MINOS originates from aged biomass burning smoke and are likely to be functionalized (Andreae, 1991; Cachier 1998), thus with different chemical properties compared to urban carbonaceous aerosols (fossil fuel origin).

To better assess the origin of $\mathrm{BC}$ during the MINOS campaign, both $\mathrm{BC}(\mathrm{IMPROVE})$ and $\mathrm{BC}($ Thermal) were compared with sub micron nss-K used here as a tracer for biomass burning (see for instance Andreae 1983, Echalar et al., 1995 and 1998) and with sub micron nss-SO $\mathrm{SO}_{4}$ used here 
as a tracer for fossil fuel combustion. $\mathrm{BC}$ concentrations have been set to the same scale in Fig. 2 to better emphasize the difference in concentration between the two EGA's. Most of the time a good agreement was found between BC (Thermal) and nss- $\mathrm{SO}_{4}$ (when the two biomass burning events are removed, nss- $\mathrm{SO}_{4}=0.09 \mathrm{BC}+0.44 ; r^{2}=0.47 ; \mathrm{n}=39$ ). When the three anthropogenic periods reported in Fig. 2 are delineated and analyzed separately, correlation between $\mathrm{BC}$ (Thermal) and nss- $\mathrm{SO}_{4}$ becomes even more significant (correlation coefficients of $0.77,0.95$ and 0.95 for the 3 periods respectively).

On the other hand, BC (IMPROVE) is better correlated with nss- $\mathrm{K}$ (nss- $\mathrm{K}=0.51 \mathrm{BC}-0.16 ; r^{2}=0.89$ : $\mathrm{n}=56$ ). When the two biomass burning periods reported in Fig. 2 are delineated corresponding data (BC(IMPROVE) and nss-K ) shows an even better correlation $\left(r^{2}=0.91\right)$. In more details, the three anthropogenic events reported in Fig. 2 are observed in BC (Thermal), whereas BC (IMPROVE) remains "insensitive" to these events. Conversely the two biomass burning events reported in this figure are observed in BC (IMPROVE), whereas BC (Thermal) remains "insensitive" to these events. Such results are quite striking and, to our best knowledge, have never been reported in the literature. In the following, we tentatively explain the reasons why BC (Thermal) and BC (IMPROVE) could be exclusively sensitive to anthropogenic and biomass burning emissions respectively.

\subsection{Comparison with absorption measurements}

Alternatively, the levels of $\mathrm{BC}$ in aerosols can be also approached from their light absorbing properties. Absorption measurements were performed for that purpose during the campaign using a PSAP, and were compared with BC(IMPROVE) in Fig. 3. Absorption measurements performed from the PSAP were corrected from the multiple scattering induced by the aerosol deposit and misinterpreted as absorption (Bond et al., 1999). As shown in the Fig. 3, a significant correlation is found between the two datasets $\left(r^{2}=0.90 ; \mathrm{n}=54\right)$. This correlation reaches $0.93(\mathrm{n}=15)$ when the dataset is restricted to the two biomass burning events (Fig. 2). This is not really a surprising result since the split point between BC and OC in the Thermo-optical method is precisely based on the optical properties of aerosols measured also by the PSAP. On the contrary, when PSAP absorption measurements (Abs (PSAP)) are compared with BC (Thermal) or nss-SO $\mathrm{S}_{4}$, no correlation is obtained. In other words, optical and thermo-optical measurements behave the same and seem to be entirely related to biomass burning whereas anthropogenic emissions are only reflected in the thermal measurements. Note that these results should not lead to misinterpretation such as BC (Thermal) concentrations being entirely representative of the anthropogenic fraction of BC. The same caution has to be taken to interpret the $\mathrm{BC}$ (IMPROVE) concentrations as being entirely representa-

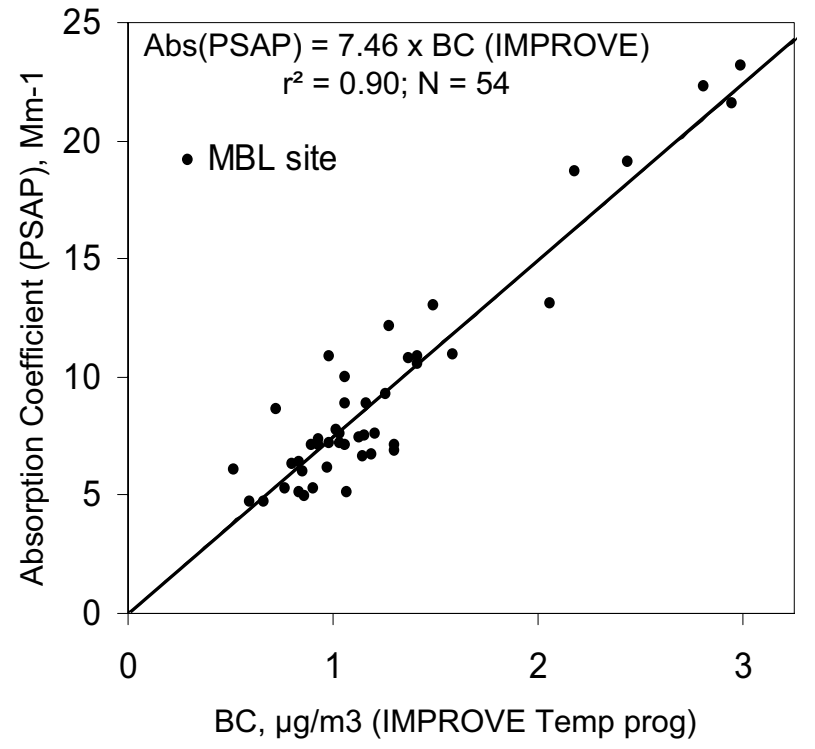

Fig. 3. Correlation between $\mathrm{BC}$ concentration (IMPROVE Temp prog.) and absorption measurements performed in the field from PSAP. PSAP data are corrected from multiple scattering following the recommendation of Bond et al. (1999).

tive for the biomass burning fraction of $\mathrm{BC}$.

\section{On the reason why $\mathrm{BC}$ (Thermal) better correlates with fossil fuel combustion}

The presence of potassium and sodium in aerosols may oxidize $\mathrm{BC}$ particles, and thus decrease their temperature of combustion (Novakov and Corrigan, 1995). Martins et al. (1998) reached the same conclusion from the analysis of biomass burning smoke samples by the 2-step thermal method used here (Cachier et al., 1989). Martins et al. (1998) found that samples with K/BC (Thermal) mass ratios higher than 0.78 were significantly influenced by catalytic reactions between $\mathrm{BC}$ and $\mathrm{K}$, inducing an underestimation of $\mathrm{BC}$ ( Thermal). Our K/BC (Thermal) mass ratio typically averaged $0.4 \pm 0.2$ with values exceeding 0.8 during the two biomass burning events depicted in Fig. 2. Then, during these events a significant fraction of $\mathrm{BC}$ originating from biomass burning was removed during the first oxidative step of our thermal method. The remaining fraction of $\mathrm{BC}$, determined as $\mathrm{BC}$ (Thermal), correlates with nss- $\mathrm{SO}_{4}$ and thus has an anthropogenic origin. Note that the conclusion of the existence of a significant $\mathrm{BC}$ fraction of anthropogenic origin cannot be reached from optical or thermo-optical measurements, which look very sensitive to biomass burning. A major question is thus raised here on the reliability of optical and thermo-optical methods (PSAP, IMPROVE) in determining BC content for a mixture of carbonaceous aerosol from different sources. 


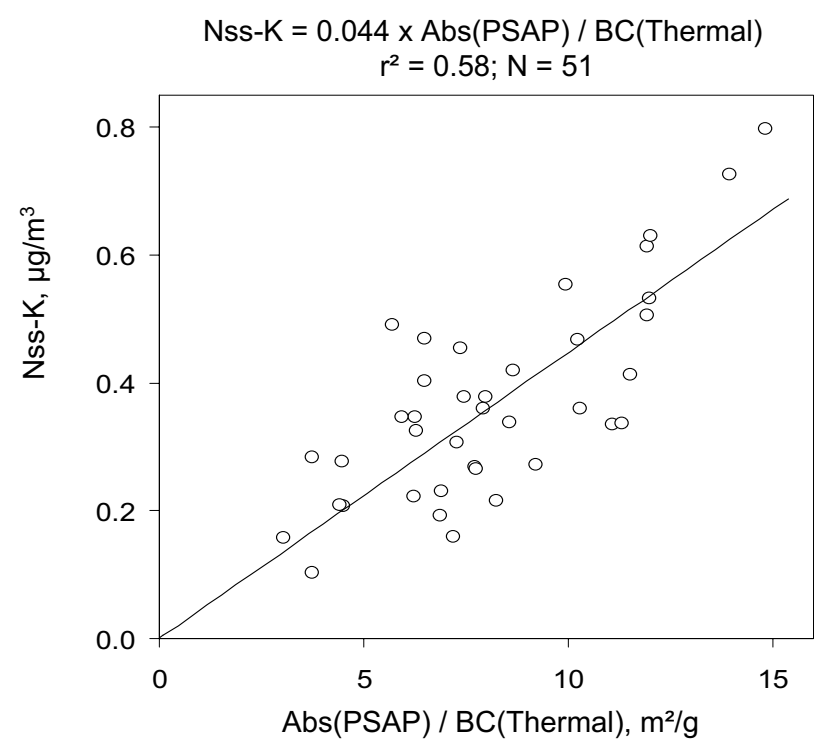

Fig. 4. Correlation between nss-K concentration and the mass absorption efficiencies (MAE) calculated from the ratios Abs (PSAP) and BC (Thermal). The first biomass burning event has been excluded.

\section{On the reason why absorption measurements better correlate with biomass burning}

A possible explanation could originate from different Mass Absorption Efficiencies (MAE) for biomass burning and fossil fuel combustions respectively. This coefficient can be estimated from the relationship:

$\mathrm{Abs}=\mathrm{MAE} \times \mathrm{BC}$

A higher MAE for biomass burning would induce a higher sensitivity of optical measurements as it appeared here. This observation is strengthen by the results of the work of Liousse et al. (1993) who reported the highest MAE (of $20 \mathrm{~m}^{2} / \mathrm{g}$ ) for biomass burning aerosol. For smoke aerosols, many authors use a model based on a highly absorbing BC core surrounded by a nonabsorbing shell (Martins et al., 1998, and references therein). This internal mixture leads to higher MAE than pure BC particles and can reasonably well explain the observed absorption sensitivity to biomass burning.

Further considerations on the influence of Biomass Burning on Absorption measurements: From a source-receptor model, Sciare et al. (2003) reported that the main sources of $\mathrm{BC}, \mathrm{SO}_{2}$ and nss- $\mathrm{SO}_{4}$ observed at the same MBL sampling station during the summer of 2000 were located in central Europe and would probably correspond to coal power plant emissions. This result is supported by the $\mathrm{SO}_{2}$ emission maps provided by UNECE/EMEP and available from the EMEP website (http://www.emep.int) and by observa- tions of $\mathrm{SO}_{2}$ over northern Greece (Zerefos et al., 2000; Formenti et al., 2001).

During this summer 2000, the eastern Mediterranean Sea was not influenced by biomass burning and Sciare et al. (2003) reported a significant correlation between BC (from PSAP measurements) and nss- $\mathrm{SO}_{4}$ in aerosols. This result goes well with an exclusive fossil fuel origin for $\mathrm{BC}$ but it is completely different from the one obtained during the MINOS campaign. These contrasted results support the previous findings on higher MAE for biomass burning compared to fossil fuel combustion during the MINOS campaign.

All these results bring to our attention an important limitation of the thermo-optical and optical methods in determining $\mathrm{BC}$ concentration in a mixture of carbonaceous aerosols from different sources. The thermo-optical methods are based on an optical correction and, for that reason, will critically be influenced by the source of $\mathrm{BC}$ having the highest MAE (biomass burning in our study).

\section{Mass absorption efficiency calculation}

We demonstrated before that significant artifacts could have altered both BC(IMPROVE) and BC (Thermal) concentration results. One must keep in mind these limitations in the following calculations of the MAE. We can estimate here a MAE from our two BC datasets using Eq. (1).

We reported in Fig. 4 the ratio between Abs (PSAP)/BC (Thermal) versus the nss-K concentration. This ratio can be seen as the MAE of BC (expressed in $\mathrm{m}^{2} / \mathrm{g}$ ) and calculated for each sample. It can be seen also as the relative contribution of biomass burning to fossil fuel combustion. As shown on this figure the decrease of $\mathrm{BC}$ (Thermal) relative to Abs (PSAP) is proportional to the increase of nss-K. It can be interpreted as the influence of the catalytic reaction between $\mathrm{BC}$ and potassium (see the previous discussion in Sect. 4.2). But it can also interpreted as an increase of MAE when moving to higher $\mathrm{BC}$ contribution from biomass burning (e.g. higher nss-K). Conversely, it can be interpreted as a decrease of MAE when moving to higher BC contribution from fossil fuel combustion (e.g. lower nss-K). This result fits the assumption that MAE is more important for biomass burning $\mathrm{BC}$ particles. Based on thermo-optical measurements, this coefficient remains fairly constant at $7.5 \pm 1.5 \mathrm{~m}^{2} / \mathrm{g}$ (Fig. 3), and thus is not sensitive to different mixture of biomass burning and fossil fuel combustion as observed previously.

An independent calculation can be done to estimate this MAE from the model described by Martins et al. (1998) for smoke particles, and assuming a BC core with a surrounding nonabsorbing shell (ammonium sulfate and organic carbon). Taking a size distribution for BC centered at $0.4 \mu \mathrm{m}$ Aerodynamic Equivalent Diameter (A.E.D) (see later on), and a mass ratio $\mathrm{BC} /($ Ammonium Sulfate + Particulate Organic Matter, POM) of $7.5 \%$ as calculated during the campaign, we 


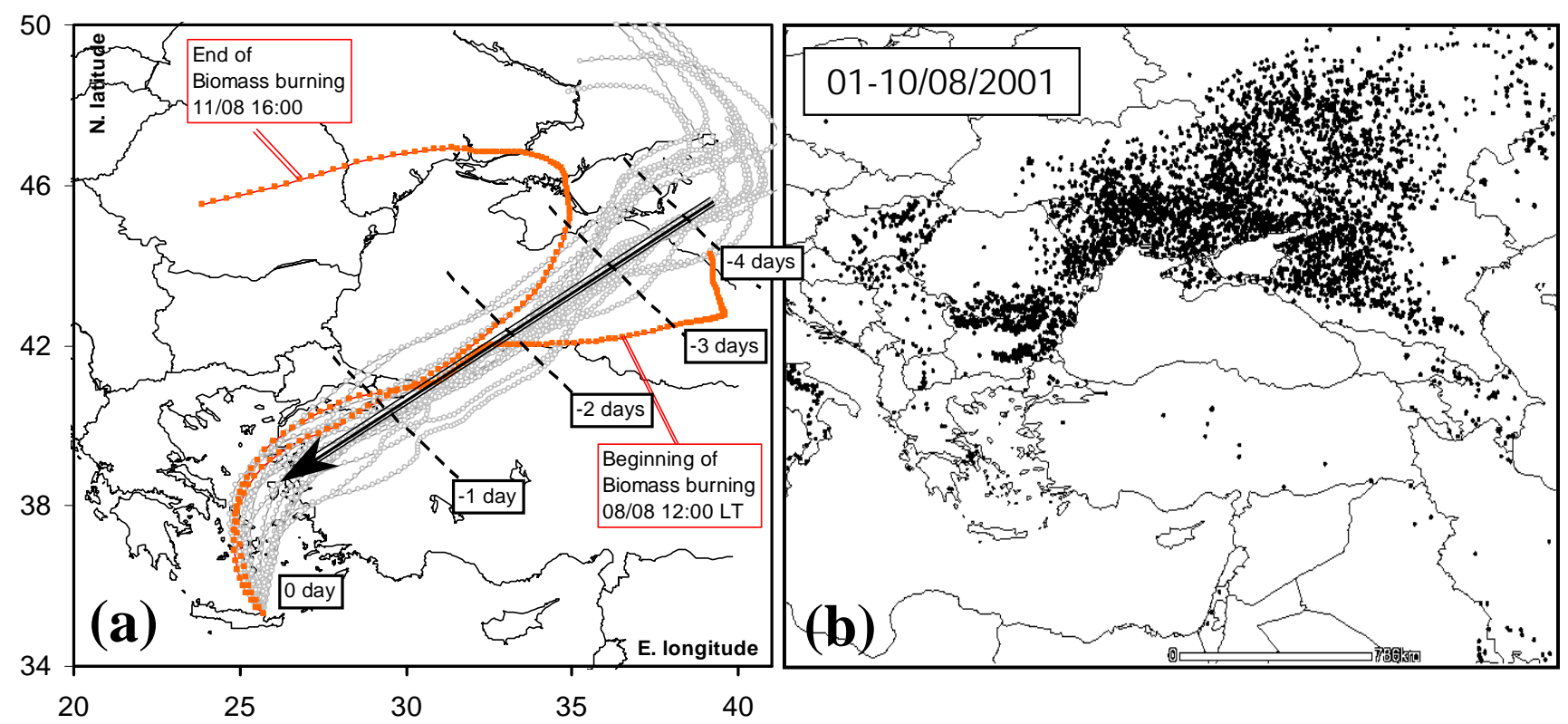

Fig. 5. (a) 5-day back trajectories generated every $4 \mathrm{~h}$ from the HYSPLIT model for the period (08 August, 12:00 LT-11 August, 16:00 LT). The back trajectories are arriving at $500 \mathrm{~m}$ asl. Those set in red correspond to the beginning and the end of the first biomass burning depicted in Fig. 3. A Temporal scale has been added to better the location of air masses. (b) Fire maps (MODIS satellite) available at http://firemaps.geog.umd.edu/. Each black point corresponds to a fire for the first 10 days of August 2001.

obtain a MAE of the order of $7-8 \mathrm{~m}^{2} / \mathrm{g}$, in good agreement with the previous calculations.

\section{Origin and size distribution of carbonaceous aerosols}

The only source reported in literature for acetonitrile is biomass burning (Holzinger et al., 1999; 2001). Measurements of this compound were performed during the MINOS campaign and reported by Salisbury et al. (2003) who reached the conclusion that most of the time MBL air masses were influenced by biomass burning. Such result is in agreement with our correlation observed between BC (IMPROVE) and nss- $\mathrm{K}$ for the whole campaign duration. The most important biomass burning event is observed on BC (IMPROVE) for the period 8-12 August (Fig. 2), and reported in Fig. 5 using Hysplit 5-day back trajectories for this period, drawn every 4 hours. On this figure a MODIS map provided by http://firemaps.geog.umd.edu/ displays numerous fire spots in Ukraine, in the northern Black Sea region as well as in the western Black Sea (Bulgaria and Romania). In these regions, fires were still observed during the second 10 days of August and thus for the second biomass burning event (Fig. 2) which also originated from the northern part of the Black Sea.

\subsection{Scanning electron microcopy}

Selected Nuclepore filters collected at the MBL site have been analyzed by Analytical Scanning Electron Microscope (ASEM) Jeol 6301F fitted with an X-Rays Energy Disper- sive Spectrometer (EDS), Oxford Link Isis. SEM and Xray analysis revealed the presence of residues of incomplete wood combustion of several micrometers, composed by important content of $\mathrm{C}$ associated with $\mathrm{K}$, in agreement with the correlation between BC (IMPROVE) and nss-K observed before. This emphasizes also that super micron biomass burning aerosols can be transported in the MBL at more than $3000 \mathrm{~km}$ from their source.

Figure 6a become from the observation of particles deposited on the filters sampled on 1 August. Their sphericity, their smooth surface, their granulometry (few $\mu \mathrm{m}$ ) and their silico-aluminated chemical composition are characteristic of fly-ash emitted during coal combustion (Ramsden and Shibaoka, 1982). Same typical fly-ash have been also observed on many other samples through the MINOS campaign including the 2 major biomass burning events, and bring further evidence of a mixture of different aerosol sources The presence of coal fly-ash is consistent with the conclusions reached by Sciare et al. (2003) on the origin of anthropogenic aerosols in the eastern Mediterranean. Moreover these conclusions are confirmed by the presence of aggregates of soot particles isolated (Fig. 6b) or stacked on the fly-ash.

6.2 Attempt to estimate the fraction of $\mathrm{BC}$ originating from fossil fuel

A correlation was observed between BC( PSAP) and nss$\mathrm{SO}_{4}$ during the summer 2000 at the MBL site (report to the Sect. 4.3). A similar correlation was observed during the 

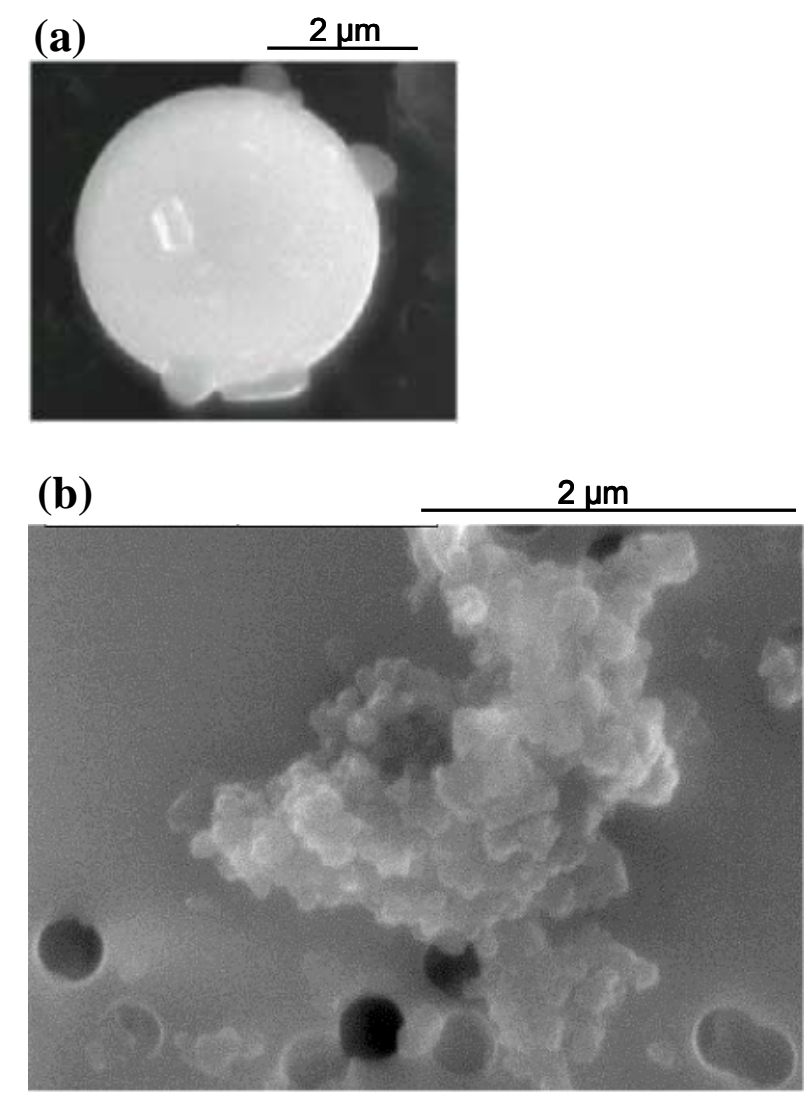

Fig. 6. Fly-ash from coal combustion (a) and carbonaceous soot particles (b) collected on $8 \mu \mathrm{m}$ and $0.4 \mu \mathrm{m}$ Nuclepore membranes respectively on 1 August 2002.

MINOS campaign between BC (Thermal) and nss-SO $\mathrm{SO}_{4}$ We propose here to use the $\mathrm{BC} / \mathrm{nss}-\mathrm{SO}_{4}$ ratio obtained during the summer 2000 as well as the nss- $\mathrm{SO}_{4}$ (and $\mathrm{SO}_{2}$ ) concentrations of the MINOS campaign to estimate the contribution of fossil fuel of this last campaign. A strong care must be taken when the $\mathrm{BC} / \mathrm{nss}-\mathrm{SO}_{4}$ ratio is used since this ratio is not conservative and will decrease with increasing oxidation of $\mathrm{SO}_{2}$ into nss-SO $\mathrm{SO}_{4}$. The mass ratio nss-SO $\mathrm{SO}_{4} /\left(\mathrm{SO}_{2}+\mathrm{nss}-\right.$ $\mathrm{SO}_{4}$ ) was calculated to be $47 \%$ and $53 \%$ for the campaigns in summer 2000 and 2001 respectively (Mihalopoulos et al., unpublished data). In other words, the fraction of $\mathrm{SO}_{2}$ oxidized in nss- $\mathrm{SO}_{4}$ is about the same for the two years and thus $\mathrm{BC} / \mathrm{nss}^{-\mathrm{SO}_{4}}$ ratios obtained in summer 2000 could be used also for summer 2001. Taking an averaged ratio of $12 \%$ for BC/nss-SO $\mathrm{S}_{4}$ typical for central/eastern Europe (Sciare et al., 2003), would lead to BC concentrations of the order of $0.7 \mu \mathrm{g} / \mathrm{m}^{3}$ for fossil fuel for summer 2001. Such concentration would represent more than half of the total BC concentration recorded during the MINOS campaign, the remaining being biomass burning. This calculation should be seen as an estimate of the order of magnitude of the fraction of $\mathrm{BC}$ originating from fossil fuel combustion, which is here comparable to the one of biomass burning contribution.
Table 2. Mass concentration $\left(\mu \mathrm{g} / \mathrm{m}^{3}\right)$ of BC, OC (IMPROVE temperature program + Thermal method), nss-K and nss-SO $\mathrm{SO}_{4}$ for the MBL site (25 July-23 August; $n=56$ ) and FT site (31 July-18 August; $\mathrm{n}=6$ for $\mathrm{BC}$ and $\mathrm{OC} ; \mathrm{n}=15$ for $\mathrm{nss}-\mathrm{K}$ and $\mathrm{nss}-\mathrm{SO}_{4}$ )

\begin{tabular}{ccc}
\hline & MBL Site (150 m asl) & FT Site $(1500 \mathrm{~m}$ asl $)$ \\
\hline BC (IMPROVE) & $1.19 \pm 0.56$ & $0.79 \pm 0.28$ \\
OC (IMPROVE) & $3.62 \pm 1.08$ & $2.70 \pm 0.49$ \\
BC (Thermal) & $1.09 \pm 0.36$ & $0.70 \pm 0.19$ \\
OC (Thermal) & $3.75 \pm 1.24$ & $2.38 \pm 0.45$ \\
nss-SO $_{4}$ & $6.19 \pm 2.21$ & $3.60 \pm 1.27$ \\
nss-K & $0.43 \pm 0.31$ & $0.26 \pm 0.11$ \\
\hline
\end{tabular}

\subsection{Carbonaceous aerosols in the FT}

Table 2 reports $\mathrm{BC}$ and TC concentrations from the two previous protocols (Thermal and IMPROVE) as well as nss-SO ${ }_{4}$ and nss-K observed at the 2 sites. The previous conclusions obtained for the MBL site on the thermal and thermo-optical $\mathrm{BC}$ values and their correlation with nss- $\mathrm{SO}_{4}$ and nss-K respectively, are applicable to the data obtained at the FT site too, suggesting also here a mix of carbonaceous aerosols of 


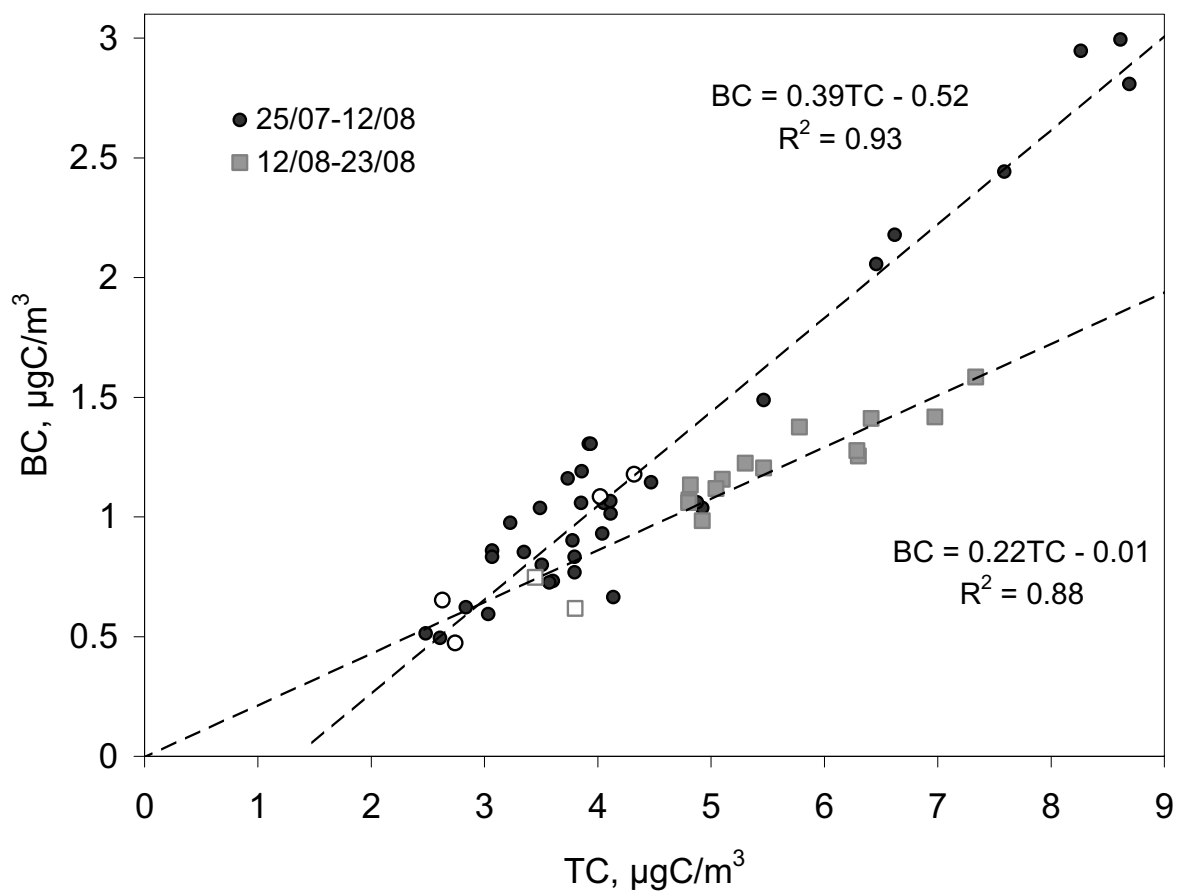

Fig. 7. BC (IMPROVE Temp program) versus TC concentrations for the 2 periods (25 July-12 August) and (12 August-23 August). Circles correspond to the first period, squares to the second. Open circles and open squares correspond to FT samples.

different origins. The correlation between BC (IMPROVE) and nss- $\mathrm{K}$ at the FT site is within the one obtained at the MBL site. Assuming a conservative ratio between $\mathrm{BC}$ and nss-K, such a result would suggest that the fraction of $\mathrm{BC}$ from biomass burning in altitude is similar as that observed in the MBL. Although there is a factor of two differences in the concentrations between the 2 sites, the two important biomass burning events observed at the MBL site are also seen at altitude (data not shown here).

\subsection{Variability of the $\mathrm{BC} / \mathrm{TC}$ ratio}

We report the $\mathrm{BC} / \mathrm{TC}$ ratio in Fig. 7 using BC (IMPROVE) for the carbon dataset from the MBL and FT sites. The good agreements between $\mathrm{BC}$ and $\mathrm{TC}$ suggest similar sources. $\mathrm{BC} / \mathrm{TC}$ ratios for the altitude site are within those found for MBL, which could indicate that the two atmospheric layers are influenced by the same sources. Two slopes are seen in this Fig. 7; before and after 12 August. This change in the slopes between BC and TC is not seen when BC (Thermal) is taken instead of BC (IMPROVE). In other words, we can reasonably assume that the changes in the $\mathrm{BC} / \mathrm{TC}$ ratios depicted in Fig. 7 are more related to biomass burning. The two biomass burning events depicted in Fig. 2 originate from the same area (Northern Black Sea, as shown in Fig. 5 for the first event) but have different slopes, suggesting different biomass burning combustion processes or/with different absorbance properties. Correlations between carbon monoxide
(CO) and $\mathrm{BC}$ measurements are widely used to characterize different combustion processes (Chen et al., 2001; Dickerson et al., 2002; Baumgardner et al., 2002) and were performed in the field using a fully automated gas chromatograph instrument for CO (Gros et al., 1998a and 1998b), and a PSAP for absorbance measurements. As mentioned earlier correlation between BC(IMPROVE) and Abs(PSAP) was excellent all along the duration of the campaign; Abs(PSAP) was used together with CO instead of BC (IMPROVE) in order to provide a better temporal resolution of their ratio. A change in the Abs (PSAP)/CO ratio was observed also on $12 \mathrm{Au}$ gust, which was not related in its slope but in its intercept (decrease of absorbance by a factor of 2 relatively to $\mathrm{CO}$ ). This shift fits that observed for the $\mathrm{BC} / \mathrm{TC}$ ratio the same day and thus brings further evidence of different combustion processes (with different optical properties) observed before and after 12 August.

\subsection{Size distribution of $\mathrm{BC}, \mathrm{OC}$ and $\mathrm{BC} / \mathrm{TC}$ ratio}

A total of 5 size distributions of $\mathrm{BC}$ and $\mathrm{TC}$ (Thermal method) were obtained at the MBL site from a 13-stage Impactor (DEKATI) and a time resolution of around 3 days. Contrarily to thermo-optical methods, the 2-step thermal method used here does not require homogeneous deposit of aerosol on the filter and thus is well adapted to the nonuniform and concentrated deposit of the filters collected with the DEKATI Impactor. 


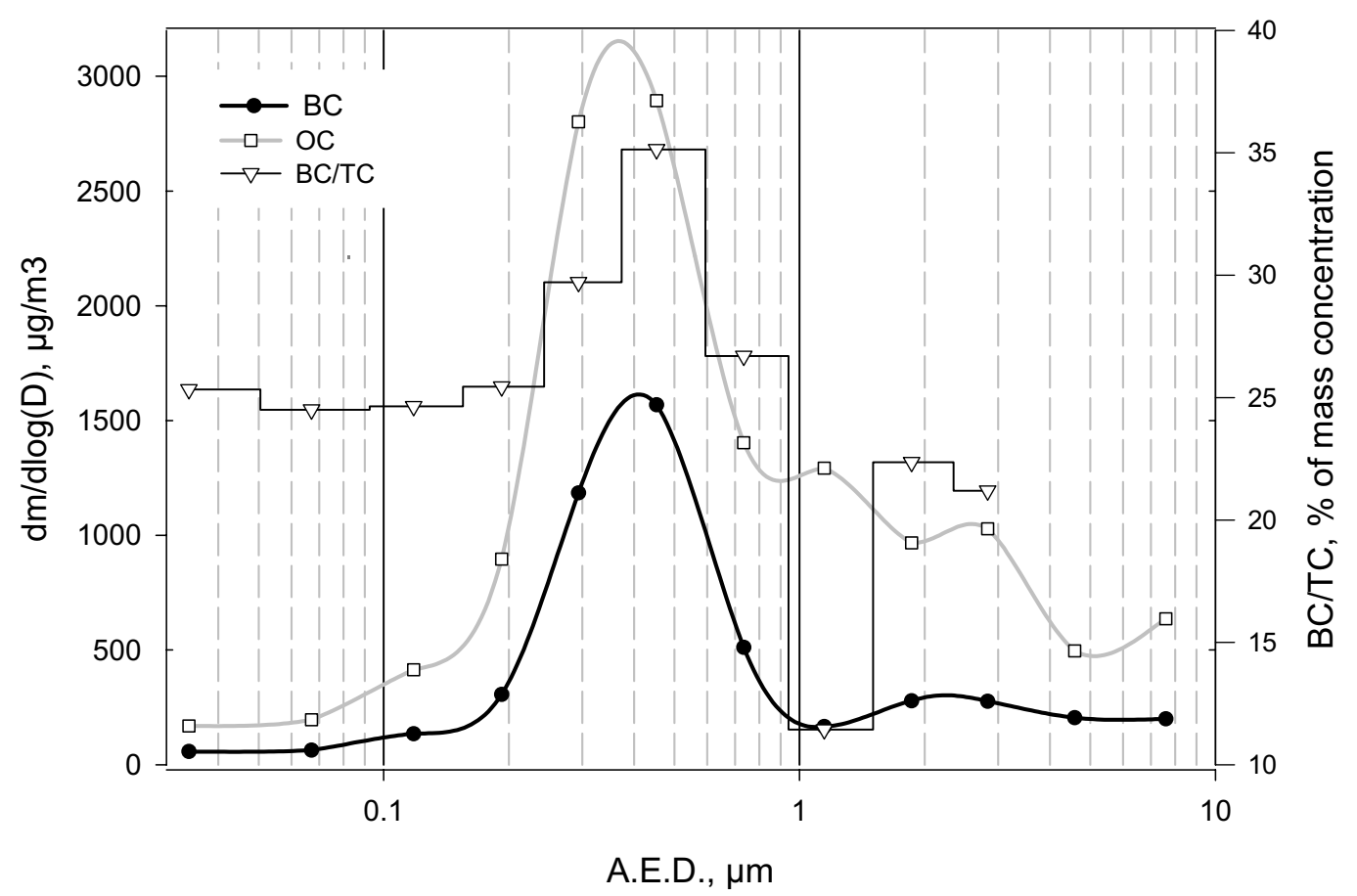

Fig. 8. Averaged mass size distribution of BC, OC and BC/TC ratio from the 2-step thermal method.

Averaged size distribution for $\mathrm{BC}$, $\mathrm{OC}$ and $\mathrm{BC} / \mathrm{TC}$ are reported in Fig. 8. Two modes around $0.4 \mu \mathrm{m}$ and $3 \mu \mathrm{m}$ Aerosol Equivalent Diameter (A.E.D.) for both BC and OC are found all along the campaign, the sub micron mode representing around $80 \pm 3 \%$ and $75 \pm 12 \%$ of their total mass respectively. The nss-K distribution obtained in parallel from the MOUDI impactor presents also a clear mode around $0.4 \mu \mathrm{m}$, which represents almost $90 \%$ of its total mass.

An interesting result comes from an extra mode present for $\mathrm{OC}$ around $1 \mu \mathrm{m}$ A.E.D and observed all along the campaign. This mode does not correlate with $\mathrm{BC}$, nss-K or nss- $\mathrm{SO}_{4}$ distributions; it corresponds to the lowest $\mathrm{BC} / \mathrm{TC}$ ratio (Fig. 8), and thus has little chance to originate from primary combustion processes. Interestingly is the correspondence between the two supermicron modes of OC with two modes observed on the sea salt distribution as well as on nitrate and light organics such as oxalate (results from the MOUDI impactor; Sciare et al., manuscript in preparation). This fraction of super micron OC is not negligible $(\approx 20 \%$ of the total mass) and would suggest adsorption processes of acidic gases (VOCs) onto basic sea salt particles similar to that observed for oxalate and nitrate (Bardouki et al., 2003).

On the Choice of the 2-step thermal method for determining $\mathrm{BC}$ and $\mathrm{OC}$ mass size distribution

As mentioned before, the non-uniform deposit of aerosols obtained on the DEKATI cascade impactor filters does not allow any optical corrections as done with a thermo-optical method. The split between $\mathrm{BC}$ and $\mathrm{OC}$ requires other methodologies, that are often based on parallel sampling of cascade impactor with quartz filters (see for instance Viidanoja et al., 2002 and Matta et al., 2002). A correction of $\mathrm{BC}$ from pyrolytic $\mathrm{OC}$ is then calculated from these quartz filters and is applied for all the stages of the cascade impactor to derive $\mathrm{BC}$ and $\mathrm{OC}$ concentrations. To do so, one must make the assumption that thermal properties (and corresponding pyrolytic OC) of carbonaceous aerosols do not depend on the size distribution. Our supermicron fraction of OC, which probably originates from condensation of VOCs onto sea salt particles, has little chance to have thermal properties similar to submicron OC. Hence, and due to its relatively small contribution to the total mass of $\mathrm{OC}$, this supermicron fraction will not significantly influence the pyrolytic OC correction of BC which could be performed from our quartz filters sampled in parallel of our cascade impactor. The above assumption that thermal properties of carbonaceous aerosols do not depend on the size is not applicable in our samples and would probably lead to a misinterpretation of the supermicron fraction of OC. The 2-step thermal method used here in our DEKATI impactor samples is probably partially affected by artifacts (potassium catalytic reaction, report to Sect. 4.2). On the other hand, it offers an interesting alternative to the methodologies currently used to estimate the $\mathrm{BC}$ and $\mathrm{OC}$ mass size distribution and highlight here a non-negligible source of secondary OC. 


\section{Conclusions}

Along the MINOS campaign, air masses were influenced by long-range transport of biomass burning located in the northern and western Black Sea, at more than $2000 \mathrm{~km}$ from the receptor site in Crete Isl.. Evidence was brought that an important fraction of carbonaceous aerosols collected in Crete was originating from these biomass burning events (back trajectory analysis, SEM analysis, correlation between BC and nss-K, gas phase measurements). The monthly mean Black Carbon concentration calculated for the summer 2001 is a factor of 3 higher compared to the one calculated a year before at the same location. Its composition is a complex mixture from different origins (biomass burning, fossil fuel) having different optical properties and mixing state. These results highlights at least the need for multiple year measurements for carbonaceous aerosols in Crete Isl., as such datasets would be used lately for validating models calculating the direct radiative forcing of aerosols over the eastern Mediterranean Sea.

We have brought here evidence that three widely used analytical procedures for determining $\mathrm{BC}$ and $\mathrm{OC}$ failed to fully characterize a complex mixture of aerosols originating from biomass burning and fossil fuel combustions (e.g. NIOSH and IMPROVE thermo-optical protocols as well as a 2-step Thermal protocol).

Dust aerosols have shown to interfere with the determination of $\mathrm{BC}$ and $\mathrm{OC}$ in the NIOSH method. Attention was brought that filter-based absorption measurements performed during the campaign (PSAP or Aethalometer) as well as the IMPROVE thermo-optical method were significantly influenced by the optical properties of the $\mathrm{BC}$ fraction originating from biomass burning and thus could have possibly underestimated the anthropogenic fraction of BC. Valuable information on the origin of $\mathrm{BC}$ and $\mathrm{OC}$ could be obtained from the 2-step Thermal method and evidenced a non-negligible fraction of BC originating from fossil fuel combustion. Furthermore, this 2-step thermal method was applied satisfactorily to the analysis of heterogeneous impactor samples and could show the existence of a supermicron OC mode that could be of secondary origin. In the absence of an universal analytical protocol for particulate carbon, these findings highlight the need for further crossed comparison exercises between different methods for determining $\mathrm{BC}$ and $\mathrm{OC}$ at locations influenced by different aerosol sources, as observed in the eastern Mediterranean Sea. It points out also the strong care needed when designing a single and common analytical protocol for carbon analysis within network and intensive field studies.

Acknowledgements. The authors want to acknowledge here François Gautier and Olivier Favez for their important contribution in sampling and analysis the carbonaceous aerosols at the two sampling sites. We wish also to thank S. G. Jennings for the review of this manuscript and ECPL team for its help in the field as well as for its hospitality. M. O. Andreae and J. Lelieveld are gratefully thanks for the opportunity given to J. Sciare and the LSCE team to participate to the MINOS campaign. This work has been supported by LSCE and MPI.

\section{References}

Andreae, M. O.: Soot carbon and Excess fine Potassium: LongRange Transport of Combustion-derived Aerosols, Science, 220, 1148-1151, 1983.

Andreae, M. O.: Biomass burning: Its history, use, and distribution and its impact on environmental quality and global climate, in Global Biomass Burning: Atmospheric, Climatic, and Biospheric Implications, edited by Levine, J. S., pp. 3-21, MIT Press, Cambridge, Mass., 1991.

Andreae, T. W., Andreae, M. O., Ichoku, C., Maenhaut, W., Cafmeyer, J., Karnieli, A., and Orlovsky, L.: Light scattering by dust and anthropogenic aerosol at a remote site in the Negev desert, Israel, J. Geophys. Res., 107, 10.1029/2001JD900252, 2002.

Bardouki, H., Liakakou, H., Economou, C., Sciare, J., Smolik, J., Zdimal, V., Eleftheriadis, K., Lazaridis, M., Dye, C., and Mihalopoulos, N.: Chemical composition of size-resolved of atmospheric aerosols in the Eastern Mediterranean during summer and winter, Atmos. Environ., 37, 195-203, 2003.

Baumgardner, D., Raga, G., Peralta, O., Rosas, I., and Castro, T., Kuhlbusch, T., John, A., Petzold, A.: Diagnosing black carbon trends in large urban areas using carbon monoxide measurements, J. Geophys. Res., 107 (D21), 8342, doi:10.1029/2001JD000626, 2002.

Birch, M. E.: Analysis of Carbonaceous aerosols: Interlaboratory comparison, Analyst, 123, 851-857, 1998.

Birch, M. E. and Cary, R. A.: Elemental carbon-base method for monitoring occupational exposures to particulate diesel exhaust, Aer. Sci. Technol., 25, 221-241, 1996

Bond, T. C., Anderson, T. L., and Campbell, D.: calibration and intercomparison of filter-based measurements of visible light absorption by aerosols, Aerosol Sci. and Technol., 30, 582-600, 1999

Cachier, H., Brémond, M. P., and Buat-Ménard, P.: Determination of atmospheric soot carbon with a simple thermal method. Tellus 41B, 379-390, 1989

Cachier, H.: Carbonaceous Combustion Aerosols, in Atmospheric Particles, edited by Harrison, R. M. and Van Grieken, R., J. Wiley \& Sons Ltd, New York, 295-348, 1998.

Cachier, H.: CARAMEL EC Program, EVK4-2000-00662, 2nd year report, 2003.

Chen, L.-W. A., Doddridge, B. G., Dickerson, R. R., and Mueller, P. K.: Seasonal variations in elemental carbon aerosol, carbon monoxide, and sulfur dioxide: Implications for sources, Geophys. Res. Lett., 28(9), 1711-1714, 2001.

Chow, J. C., Watson, J. G., Pritchett, L. T., Pierson, W. R., Frazier, C. A., and Purcell, R. G.: The DRI Thermal/Optical Reflectance Carbon Analysis System: Evaluation and Applications in U.S. Air Quality Studies, Atmos. Environ., 27A, 1185-1201, 1993.

Chow, J. C., Watson, J. G., Crow, D., Lowenthal, D. H., and Merrifield, T.: Comparison of IMPROVE and NIOSH carbon measurements, Aer. Sci. Technol., 34, 23-34, 2001.

Conny, J. M. and Slater, J. F.: Black Carbon and Organic carbon in aerosol particles from crown fires in the Canadian boreal forest, 
J. Geophys. Res., 107, 11, 10.129/2001JD001528, 2002.

Dickerson, R. R., Andreae, M. O., Campos, T., Mayol-Bracero, O. L., Neusuess, C., and Streets, D. G.: Analysis of Black Carbon and Carbon Monoxide Observed over the Indian Ocean: Implications for Emissions and Photochemistry, J. Geophys. Res., 107(19), 8017, doi:10.1029.2001JD000501, 2002.

Draxler, R. R. and Hess, G. D.: An overview of the HYSPLIT_4 modelling system for trajectories, dispersion and deposition, Aust. Met. Mag. 47, 295-308, 1998.

Echalar, F., Gaudichet, A., Cachier, H., and Artaxo, P.: Aerosol emissions by tropical forest and savanna biomass burning: charasteristic trace elements and fluxes, Geophys. Res. Lett., 22, 3039-3042, 1995.

Echalar, F., Artaxo, P., Martins, J. V., Yamasoe, M., Gerab, F., Maenhaut, W., Holben, B.: Long-Term monitoring of atmospheric aerosols in the Amazon Basin: Source identification and apportionment, J. Geophys. Res., 103, 31 849-31 864, 1998.

Formenti, P., Andreae, M. O., Andreae, T. W., Galani, E., Vasaras, A., Zerefos, C., Amiridis, V., Orlovsky, L., Karnieli, A., Wendisch, M., Wex, H., Holben, B. N., Maenhaut, W., and Lelieveld, J.: Aerosol optical properties and large-scale transport of air masses: Observations at a coastal and semiarid site in the eastern Mediterranean during summer 1998, J. Geophys. Res., 106, 9807-9826, 2001.

Formenti, P., Boucher, O., Reiner, T., Sprung, D., Andreae, M. O., Wendish, M., Wex, H., Kindred, D., Tzortziou, M., Vasaras, A., and Zerefos, C.: SAAARTE6MED 1998 summer airborne measurements over the Aegean Sea: 2. Aerosol scattering and absorption, and radiative calculations, J. Geophys. Res., 107, D21, 4451, doi:10.1029/2001JD001536, 2002.

Gros, V., Sarda-Estève, R., Bonsang, B., and Ramonet, M.: Mesure du monoxyde carbone par chromatographie en phase gazeuse, rapport CEA n ${ }^{\circ} 8514$, Ed. Direction de l'information scientifique et technique, CEA Saclay, Gif Sur Yvette, France, 1998a.

Gros, V., Bonsang, B., Martin, D., and Novelli, P. C.: Carbon monoxide short term measurements at Amsterdam Island: Estimation of biomass burning rates, Chemosphere, Global Change Science 1, 163-172, 1998b.

Guillemin, M., Cachier, H., Chini, C., Dabill, D., Dahmann, D., Diebold, F., Fischer, A., Fricke, H.-H., Groves, J. A., Hebisch, R., Houpillart, M., Israel, G., Mattenklot, M., Moldenhauer, W., Sandino, J. P., Schlums, C., Sutter, E., and Tucek, E.: International round robin tests on the measurements of carbon in diesel exhaust particulates. International Archives of Occupational and Environmental Health, 70, 161-172, 1997.

Hansen, A. D. A., Rosen, H., and Novakov, T.: Real-Time measurement of the absorption coefficient of aerosol particles, Appl. Opt., 21, 3060-3062, 1982.

Huebert, B. J. and Charlson, R. J.: Uncertainties in data on organic aerosols, Tellus, 52B, 1249-1255, 2000.

Holzinger, R., Warneke, C., and Hansel, A.: Biomass burning as a source of formaldehyde, acetaldehyde, methanol, acetone, acetonitrile, and hydrogen cyanide, Geophys. Res. Letters, 26, 1161-1164, 1999.

Holzinger, R., Jordan, A., Hansel, A., and Lindinger, W.: Automobile emissions of acetonitrile: assessment of its contribution to the global source, J. Atmos. Chem., 38, 187-193, 2001.

Jacobson, M. Z.: Global direct radiative forcing due to multicomponent anthropogenic and natural aerosols, J. Geophys. Res., 106,
1551-1568, 2001.

Kouvarakis, G., Doukelis, Y., Mihalopoulos, N., Rapsomanikis, S., Sciare, J., and Blumthaler, M.: Chemical, physical and optical characterization of aerosol during PAUR II experiment, J. Geophys. Res., 107, D18, 8141, doi:10.1029/2000JD000291, 2002.

Kouvarakis, G., and N. Mihalopoulos, Seasonal variation of dimethylsulfide in the gas phase and of methanesulfonate and non-sea-salt sulfate in the aerosol phase measured in the eastern Mediterranean atmosphere, Atmos. Environ., 36, 6, 929-938, 2002.

Krivacsy, Z., Hoffer, A., Sarvari, Zs., Temesi, D., Baltensperger, U., Nyeki, S., Weingartner, E., Kleefeld, S., and Jennings, S. G.: Role of organic and black carbon in the chemical composition of atmospheric aerosol at European background sites, Atmos. Environ., 6131-6244, 2001.

Lelieveld, J., Berresheim, H., Borrmann, S., Crutzen, P. J., Dentener, F. J., Fischer, H., Feichter, J., Flatau, P. J., Heland, J., Holzinger, R., Korrmann, R., Lawrence, M. G., Levin, Z., Markowicz, K. M., Mihalopoulos, N., Minikin, A., Ramanathan, V., de Reus, M., Roelofs, G. J., Scheeren, H. A., Sciare, J., Schlager, H., Schultz, M., Siegmund, P., Steil, B., Stephanou, E. G., Stier, P., Traub, M., Warneke, C., Williams, J., and Ziereis, H.: Global Air Pollution Crossroads over the Mediterranean, Science, 298, 794-799, 2002.

Liousse, C., Cachier, H., and Jennings, S. G.: Optical and thermal measurements of black carbon aerosol content in different environments: variation of the specific attenuation cross section, sigma $(\sigma)$. Atmos. Environ., 27A, 1203-1211, 1993.

Markowicz, K. M., Flatau, P. J., Ramana, M. V., Crutzen, P. J., and Ramanathan, V.: Absorbing Mediterranean aerosols lead to a large reduction in the solar radiation at the surface, Geophys. Res. Lett., 10.1029/2002GL015767, 23 October 2002.

Martins, J. V., Artaxo, P., Liousse, C., Reid, J. S., Hobbs, P. V., and Kaufman, Y. J.: Effects of black carbon content, particle size, and mixing on light absorption by aerosols from Biomass Burning in Brazil, J. Geophys. Res., 103, 32 041-32 050, 1998.

Matta, E., Facchini, M. C., Decesari, S., Mircea, M., Cavalli, F., Fuzzi, S., Putaud, J.-P., and Dell' Acqua, A.: Chemical mass balance of size-segregated atmospheric aerosol in urban area of the Po Valley, Italy, Atmos. Chem. Phys., 2, 2167-2208, 2002.

NIOSH: Elemental Carbon (Diesel exhaust), In NIOSH Manual of Analytical Methods, National Institute of Occupational Safety and Health, Cincinnati, OH, 1996.

NIOSH Method 5040: In NIOSH Manual of Analytical Methods (NMAM), 4th ed., 2nd Supplement, edited by Cassinelli, M. E., O'Connor, P. F., Supplement to DHHS (NIOSH) Publication No. 94-113, 1998.

Novakov, T. and Corrigan, C.: Thermal Characterization of biomass smoke particles, Mikrochimica Acta, 119, 157-166, 1995.

Ramsden, A. R. and Shibaoka, M.: Characterization and analysis of individual fly-ash particles from coal-fired power stations by a combination of optical microscopy, electron microscopy and quantitative electron microprobe analysis, Atmos. Environ., 16, 9, 2191-2206, 1982.

Salisbury, G., Williams, J., Holzinger, R., Gros, V., Mihalopoulos, N., Vrekoussis, M., Sarda-Estève, R., Berresheim, H., von Kuhlmann, R., Lawrence, M., and Lelieveld, J.: Ground-based PTR-MS measurements of reactive organic compounds during the MINOS campaign in Crete, July-August 2001, Atmos. 
Chem. Phys. Discuss., 3, 925-940, 2003.

Schmid, H., Laskus, L., Abraham, H. J., Baltensperger, U., Lavanchy, V., Bizjak, M., Burba, P., Cachier, H., Crow, D., Chow, J., Gnauk, T., Even, A., Ten Brink, H. M., Giesen, K.-P., Hitzenberg, R., Hueglin, C., Maenhaut, W., Pio, C., Carvalho, A., Putaud, J. P., Toom-Sauntry, D., and Puxbaum, H.: Results of the "carbon conference" international aerosol carbon round robin test stage I, Atmos. Environ., 35, 2222-2121, 2001.

Sciare, J., Bardouki, H., Moulin, C., and Mihalopoulos, N.: Aerosol sources and their contribution to the chemical composition of aerosols in the Eastern Mediterranean Sea during summertime, Atmos. Chem. Phys., 3, 291-302, 2003.

Viidanoja, J., Kerminen, V. M., and Hillamo, R.: Measuring the size distribution of atmospheric Organic and black carbon using Impactor sampling coupled with thermal carbon analysis: Method development and uncertainties, Aer. Sci. and Technol., 36, 607616, 2002.
Webb, T. L. and Kruger, J. E.: Carbonates, in: Differential Thermal Analysis, edited by MacKenzie, R. C., Academic Press, New York, pp. 303-341, 1970.

Yang, H. and Yu, J. Z.: Uncertainties in Charring correction in the Analysis of elemental and organic carbon in Atmospheric particles by Thermal/Optical methods, Environ. Sci. and Technol., 36 (23), 5199-5204, 2002.

Yu, J. Z., Xu, J., and Yang, H.: Charring Characteristics of Atmospheric Organic particulate Matter in Thermal analysis, Environ. Sci. and Technol., 36, 754-761, 2002.

Zerefos, C., Ganev, K., Kourtidis, K., Tzortsiou, M., Vasaras, A., and Syrakov, E.: On the origin of $\mathrm{SO}_{2}$ above Northern Greece, Geophys. Res. Lett., 27, 365-368, 2000. 